\title{
Ectopic Autosomal Dominant Polycystic Kidney Disease (ADPKD)—An Extremely Rare Radiological Finding
}

\author{
Manish Gupta \\ Department of Medicine, Gajra Raja Medical College, Gwalior, India \\ Email: manishgupta12@yahoo.co.in \\ Received 4 January 2014; revised 4 February 2014; accepted 11 February 2014 \\ Copyright (C) 2014 by author and Scientific Research Publishing Inc. \\ This work is licensed under the Creative Commons Attribution International License (CC BY). \\ http://creativecommons.org/licenses/by/4.0/ \\ (c) (i) Open Access
}

\begin{abstract}
ADPKD is an inherited systemic disorder that predominantly affects the kidney, but may affect other organs including liver, pancreas, brain, and arterial blood vessel. APKPD occurs worldwide affecting about 1 in 500 - 1000 people. Hypertension is the most common manifestation of ADPKD and the major contributor to renal disease progression. A definite diagnosis of ADPKD relies on image testing. Renal ultrasound is commonly used because of its cost effectiveness.
\end{abstract}

\section{Keywords}

Ectopic; Pelvic Kidney; ADPKD; Polycystic; Radiological Diagnosis

\section{Introduction}

Generally, ADPKD is the predominant amongst the inherited renal cystic diseases. ADPKD is characterized by the presence of bilateral renal cysts that gradually grow and expand over time, resulting in significantly increased total kidney volume, progressive renal injury, and ultimately, end-stage renal disease (ESRD) usually in the sixth decade of life. Our case is ADPKD with ectopic, it is a rare case and the 4th one to be reported worldwide till now. Ectopic pelvic kidney at times may be associated with aberrant iliac arteries.

\section{Case History}

Our was a 68-year-old male who presented to the clinic with complaints of loss of appetite, weakness, vomiting and lower abdominal discomfort for last fifteen days. Patient was hospitalized. On clinical examination, patient was found to be having hypertension with no other obvious palpable abdominal mass. Results of urine and blood test were deranged revealing Hemoglobin of $4.7 \mathrm{gm} \%$, serum creatinine was $6.17 \mathrm{mg} / \mathrm{dl}$ and urine with 10 - 15 
pus cells. His abdominal ultrasound showed polycystic kidneys, with left ectopic kidney in pelvis on the ipsilateral side. Computed tomography was done for confirming the ultrasound finding revealed right polycystic kidney with empty left renal fossa and also multiple thin walled hypo dense cysts of variable sizes in all segment of liver (as shown in Figure 1) which is the most common extra renal manifestation of ADPKD, while ectopic polycystic left kidney is noted in left pelvis (as shown in Figure 2). Polycystic ectopic kidney occurred most commonly on the left side of the body as was also seen in all the three cases reported so far [1]-[3].

\section{Discussion}

Renal ectopia results from the disruption of the normal embryological migration of the kidneys from the pelvis to the retroperitoneal fossa. It result from the abnormalities of ureteral bud and metanephricblastema, genetic abnormalities, teratogenic influences or from anomalous vasculature acting as a barrier [4]. The incidence of pelvic kidney is 1 in 5000 [5]. Progressive polycystic kidney in the pelvis with limited space is associated with a higher risk of complications such as pelvic insufficiency fracture, intestinal or ureteric obstruction, or acute renal failure [1].

To the best of our knowledge, we are describing the fourth case report worldwide and diagnosed as an ectopic ADPKD, although ADPKD disease is the most common hereditary cause of terminal chronic kidney disease, with an incidence of 1 in 500 - 1000 [6] The cyst cause discomfort and pain due to constant pressure on abdominal wall, flanks and back. There is also case report of ADPKD complicating a pelvic kidney by fusion [3]. The diagnosis of ADPKD in an individual relies on imaging testing [7].

\section{Conclusion}

Ectopic ADPKD is an extremely rare radiological finding. Such patients should be followed on long term basis

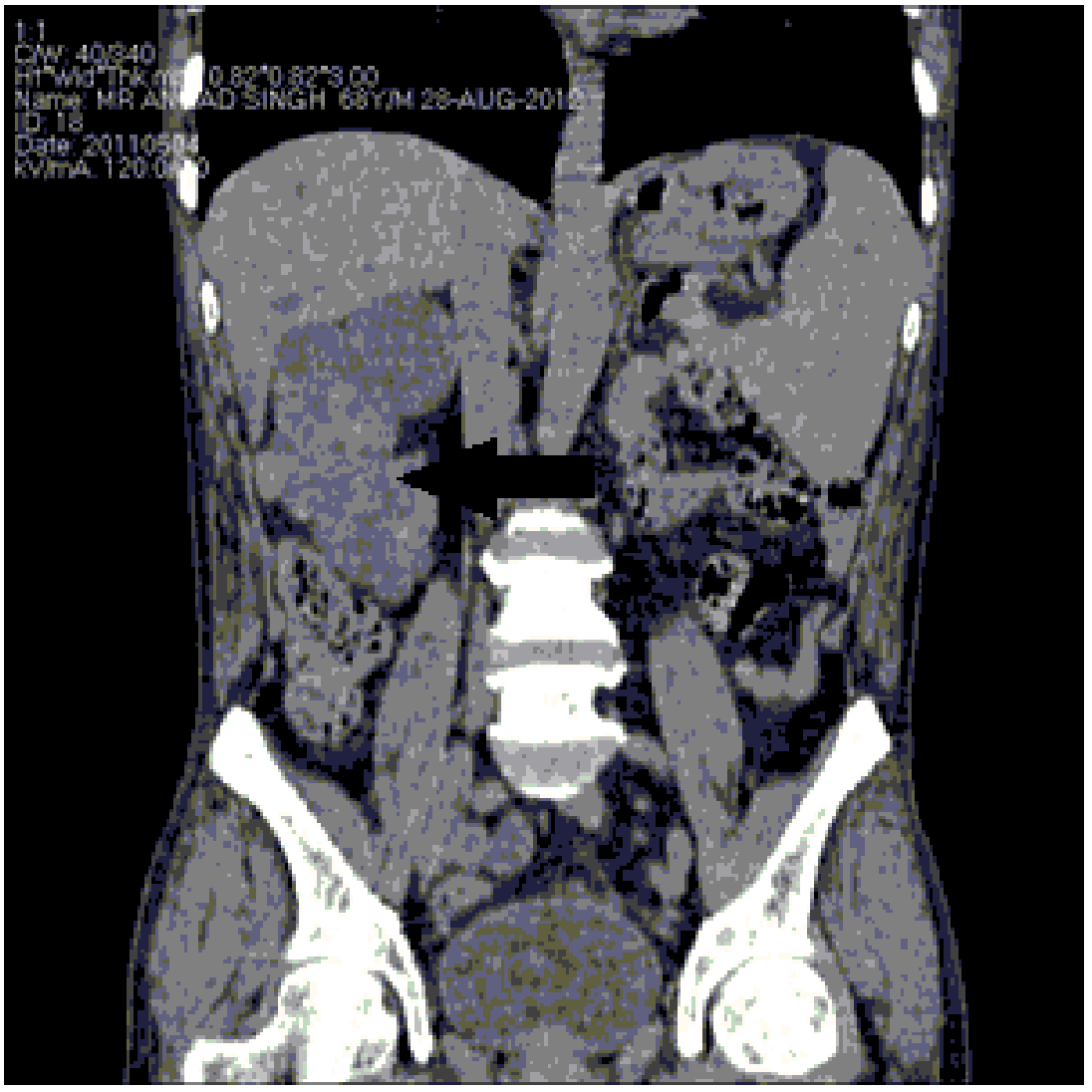

Figure 1. Abdomen Computed tomography demonstrating large right kidney (arrow) with numerous cystic masses, and liver (above kidney) with numerous cyst of variable sizes. 


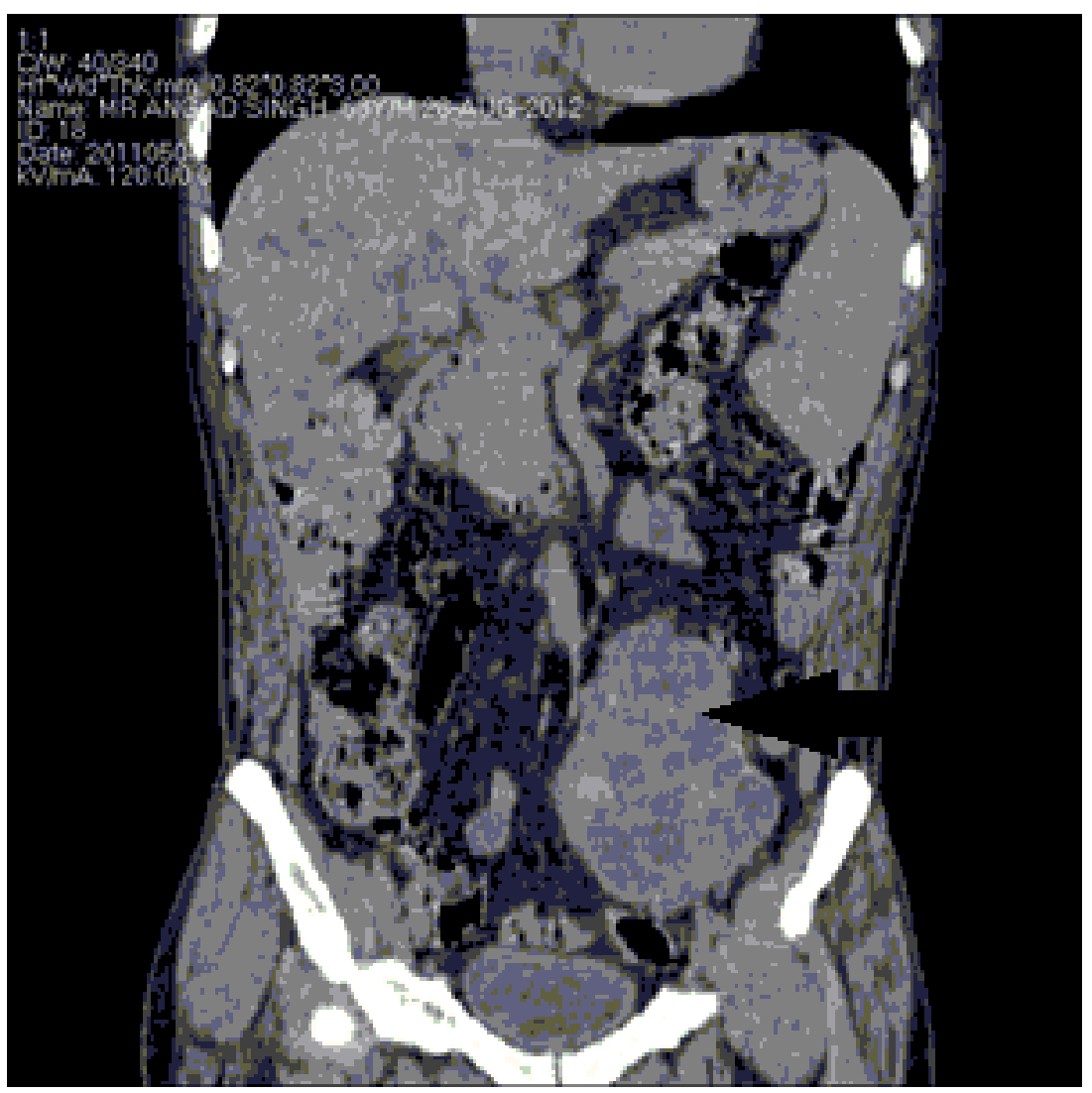

Figure 2. Computed tomography showing left ectopic polycystic kidney in ipsilateral pelvis (arrow).

and must be precariously evaluated if transplant surgery is needed.

\section{References}

[1] Chen, D.P., Ma, Y.Y., Mao, Z.G. and Mei, C.L. (2010) Ectopic (Pelvic) Autosomal Dominant Polycystic Kidney Disease. Internal Medicine, 49, 2525-2526. http://dx.doi.org/10.2169/internalmedicine.49.4415

[2] Solak, Y., Biyik, Z., Gaipov, A., Ozbek, O. and Tonbul, H.Z. (2012) Ectopic, Polycystic and Stoned: Pelvic Kidney in a Patient with Autosomal Dominant Polycystic Kidney Disease. The American Journal of the Medical Sciences, 343, 418. http://dx.doi.org/10.1097/MAJ.0b013e3182373e89

[3] Connori, A., Weston, C.E., Dick, C. and Taylori, J.E. (2009) Autosomal Dominant Polycystic Kidney Disease Complicating Renal Ectopia and Managed with Renal Transplantation. NDT Plus, 2, 420. http://dx.doi.org/10.1093/ndtplus/sfp075

[4] Malek, R.S., Kelalis, P.P. and Burke, E.C. (1971) Ectopic Kidney Tissue in Children and Frequency of Association with Other Malformation. Mayo Clinic Proceedings, 46, 461.

[5] Sheih, C.P., Liu, M.B., Hung, C.S., et al. (1989) Renal Abnormalities in School Children. Pediatrics, 84, 1086.

[6] (2012) Autosomal Dominant Kidney Disease with Contralateral Agenesis. Nefrologia, 32, 839-842.

[7] Torres, V.E., Harris, P.C. and Pirson, Y. (2007) Autosomal Dominant Polycystic Kidney Disease. Lancer, 369, 12871301. http://dx.doi.org/10.1016/S0140-6736(07)60601-1 